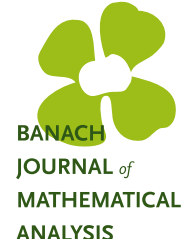

ANALYSIS
Banach J. Math. Anal. 10 (2016), no. 2, 235-250

http://dx.doi.org/10.1215/17358787-3492611

ISSN: $1735-8787$ (electronic)

http://projecteuclid.org/bjma

\title{
COMPOSITE BERNSTEIN CUBATURE
}

\author{
ANA-MARIA ACU ${ }^{*}$ and HEINER GONSKA ${ }^{2}$ \\ Communicated by R. E. Curto
}

\begin{abstract}
We consider a sequence of composite bivariate Bernstein operators and the cubature formula associated with them. The upper bounds for the remainder term of a cubature formula are described in terms of moduli of continuity of order two. Also, we include some results showing how nonmultiplicative the integration functional is.
\end{abstract}

\section{INTRODUCTION}

We reconsider (composite) bivariate Bernstein approximation and the corresponding cubature formulas. This is motivated by a recent series of articles by Bărbosu et al. (see [3], [4]). However, some of these papers contain rather misleading statements and claims which can hardly be verified. The present article is written with the intention to clean up some of the bugs, to optimize and generalize certain estimates, and thus to further describe the situation at hand.

Our present contribution is a continuation of [9]. Historically, the origin of the method discussed seems to be in the article [13] by D. D. Stancu and A. Vernescu.

\section{A GeNERAL RESULT}

We first introduce some notation that will be needed to formulate the general result.

Copyright 2016 by the Tusi Mathematical Research Group.

Received Mar. 8, 2015; Accepted May 28, 2015.

${ }^{*}$ Corresponding author.

2010 Mathematics Subject Classification. Primary 41A36; Secondary 41A15, 65D30.

Keywords. composite Bernstein operators, composite quadrature formulas, modulus of continuity. 


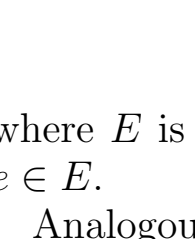

ANALYSIS
Banach J. Math. Anal. 10 (2016), no. 2, 235-250

http://dx.doi.org/10.1215/17358787-3492611

ISSN: $1735-8787$ (electronic)

http://projecteuclid.org/bjma

\title{
COMPOSITE BERNSTEIN CUBATURE
}

\author{
ANA-MARIA ACU ${ }^{*}$ and HEINER GONSKA ${ }^{2}$ \\ Communicated by R. E. Curto
}

\begin{abstract}
We consider a sequence of composite bivariate Bernstein operators and the cubature formula associated with them. The upper bounds for the remainder term of a cubature formula are described in terms of moduli of continuity of order two. Also, we include some results showing how nonmultiplicative the integration functional is.
\end{abstract}

\section{INTRODUCTION}

We reconsider (composite) bivariate Bernstein approximation and the corresponding cubature formulas. This is motivated by a recent series of articles by Bărbosu et al. (see [3], [4]). However, some of these papers contain rather misleading statements and claims which can hardly be verified. The present article is written with the intention to clean up some of the bugs, to optimize and generalize certain estimates, and thus to further describe the situation at hand.

Our present contribution is a continuation of [9]. Historically, the origin of the method discussed seems to be in the article [13] by D. D. Stancu and A. Vernescu.

\section{A GeNERAL RESULT}

We first introduce some notation that will be needed to formulate the general result.

Copyright 2016 by the Tusi Mathematical Research Group.

Received Mar. 8, 2015; Accepted May 28, 2015.

${ }^{*}$ Corresponding author.

2010 Mathematics Subject Classification. Primary 41A36; Secondary 41A15, 65D30.

Keywords. composite Bernstein operators, composite quadrature formulas, modulus of continuity. 


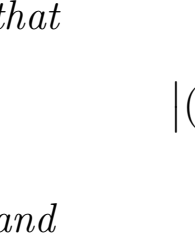

ANALYSIS
Banach J. Math. Anal. 10 (2016), no. 2, 235-250

http://dx.doi.org/10.1215/17358787-3492611

ISSN: $1735-8787$ (electronic)

http://projecteuclid.org/bjma

\title{
COMPOSITE BERNSTEIN CUBATURE
}

\author{
ANA-MARIA ACU ${ }^{*}$ and HEINER GONSKA ${ }^{2}$ \\ Communicated by R. E. Curto
}

\begin{abstract}
We consider a sequence of composite bivariate Bernstein operators and the cubature formula associated with them. The upper bounds for the remainder term of a cubature formula are described in terms of moduli of continuity of order two. Also, we include some results showing how nonmultiplicative the integration functional is.
\end{abstract}

\section{INTRODUCTION}

We reconsider (composite) bivariate Bernstein approximation and the corresponding cubature formulas. This is motivated by a recent series of articles by Bărbosu et al. (see [3], [4]). However, some of these papers contain rather misleading statements and claims which can hardly be verified. The present article is written with the intention to clean up some of the bugs, to optimize and generalize certain estimates, and thus to further describe the situation at hand.

Our present contribution is a continuation of [9]. Historically, the origin of the method discussed seems to be in the article [13] by D. D. Stancu and A. Vernescu.

\section{A GeNERAL RESULT}

We first introduce some notation that will be needed to formulate the general result.

Copyright 2016 by the Tusi Mathematical Research Group.

Received Mar. 8, 2015; Accepted May 28, 2015.

${ }^{*}$ Corresponding author.

2010 Mathematics Subject Classification. Primary 41A36; Secondary 41A15, 65D30.

Keywords. composite Bernstein operators, composite quadrature formulas, modulus of continuity. 


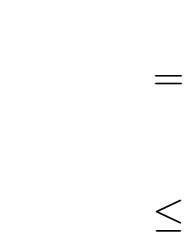

ANALYSIS
Banach J. Math. Anal. 10 (2016), no. 2, 235-250

http://dx.doi.org/10.1215/17358787-3492611

ISSN: $1735-8787$ (electronic)

http://projecteuclid.org/bjma

\title{
COMPOSITE BERNSTEIN CUBATURE
}

\author{
ANA-MARIA ACU ${ }^{*}$ and HEINER GONSKA ${ }^{2}$ \\ Communicated by R. E. Curto
}

\begin{abstract}
We consider a sequence of composite bivariate Bernstein operators and the cubature formula associated with them. The upper bounds for the remainder term of a cubature formula are described in terms of moduli of continuity of order two. Also, we include some results showing how nonmultiplicative the integration functional is.
\end{abstract}

\section{INTRODUCTION}

We reconsider (composite) bivariate Bernstein approximation and the corresponding cubature formulas. This is motivated by a recent series of articles by Bărbosu et al. (see [3], [4]). However, some of these papers contain rather misleading statements and claims which can hardly be verified. The present article is written with the intention to clean up some of the bugs, to optimize and generalize certain estimates, and thus to further describe the situation at hand.

Our present contribution is a continuation of [9]. Historically, the origin of the method discussed seems to be in the article [13] by D. D. Stancu and A. Vernescu.

\section{A GeNERAL RESULT}

We first introduce some notation that will be needed to formulate the general result.

Copyright 2016 by the Tusi Mathematical Research Group.

Received Mar. 8, 2015; Accepted May 28, 2015.

${ }^{*}$ Corresponding author.

2010 Mathematics Subject Classification. Primary 41A36; Secondary 41A15, 65D30.

Keywords. composite Bernstein operators, composite quadrature formulas, modulus of continuity. 


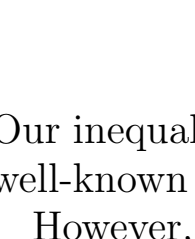

ANALYSIS
Banach J. Math. Anal. 10 (2016), no. 2, 235-250

http://dx.doi.org/10.1215/17358787-3492611

ISSN: $1735-8787$ (electronic)

http://projecteuclid.org/bjma

\title{
COMPOSITE BERNSTEIN CUBATURE
}

\author{
ANA-MARIA ACU ${ }^{*}$ and HEINER GONSKA ${ }^{2}$ \\ Communicated by R. E. Curto
}

\begin{abstract}
We consider a sequence of composite bivariate Bernstein operators and the cubature formula associated with them. The upper bounds for the remainder term of a cubature formula are described in terms of moduli of continuity of order two. Also, we include some results showing how nonmultiplicative the integration functional is.
\end{abstract}

\section{INTRODUCTION}

We reconsider (composite) bivariate Bernstein approximation and the corresponding cubature formulas. This is motivated by a recent series of articles by Bărbosu et al. (see [3], [4]). However, some of these papers contain rather misleading statements and claims which can hardly be verified. The present article is written with the intention to clean up some of the bugs, to optimize and generalize certain estimates, and thus to further describe the situation at hand.

Our present contribution is a continuation of [9]. Historically, the origin of the method discussed seems to be in the article [13] by D. D. Stancu and A. Vernescu.

\section{A GeNERAL RESULT}

We first introduce some notation that will be needed to formulate the general result.

Copyright 2016 by the Tusi Mathematical Research Group.

Received Mar. 8, 2015; Accepted May 28, 2015.

${ }^{*}$ Corresponding author.

2010 Mathematics Subject Classification. Primary 41A36; Secondary 41A15, 65D30.

Keywords. composite Bernstein operators, composite quadrature formulas, modulus of continuity. 


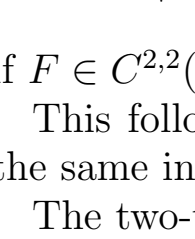

ANALYSIS
Banach J. Math. Anal. 10 (2016), no. 2, 235-250

http://dx.doi.org/10.1215/17358787-3492611

ISSN: $1735-8787$ (electronic)

http://projecteuclid.org/bjma

\title{
COMPOSITE BERNSTEIN CUBATURE
}

\author{
ANA-MARIA ACU ${ }^{*}$ and HEINER GONSKA ${ }^{2}$ \\ Communicated by R. E. Curto
}

\begin{abstract}
We consider a sequence of composite bivariate Bernstein operators and the cubature formula associated with them. The upper bounds for the remainder term of a cubature formula are described in terms of moduli of continuity of order two. Also, we include some results showing how nonmultiplicative the integration functional is.
\end{abstract}

\section{INTRODUCTION}

We reconsider (composite) bivariate Bernstein approximation and the corresponding cubature formulas. This is motivated by a recent series of articles by Bărbosu et al. (see [3], [4]). However, some of these papers contain rather misleading statements and claims which can hardly be verified. The present article is written with the intention to clean up some of the bugs, to optimize and generalize certain estimates, and thus to further describe the situation at hand.

Our present contribution is a continuation of [9]. Historically, the origin of the method discussed seems to be in the article [13] by D. D. Stancu and A. Vernescu.

\section{A GeNERAL RESULT}

We first introduce some notation that will be needed to formulate the general result.

Copyright 2016 by the Tusi Mathematical Research Group.

Received Mar. 8, 2015; Accepted May 28, 2015.

${ }^{*}$ Corresponding author.

2010 Mathematics Subject Classification. Primary 41A36; Secondary 41A15, 65D30.

Keywords. composite Bernstein operators, composite quadrature formulas, modulus of continuity. 


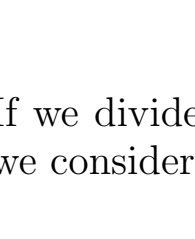

ANALYSIS
Banach J. Math. Anal. 10 (2016), no. 2, 235-250

http://dx.doi.org/10.1215/17358787-3492611

ISSN: $1735-8787$ (electronic)

http://projecteuclid.org/bjma

\title{
COMPOSITE BERNSTEIN CUBATURE
}

\author{
ANA-MARIA ACU ${ }^{*}$ and HEINER GONSKA ${ }^{2}$ \\ Communicated by R. E. Curto
}

\begin{abstract}
We consider a sequence of composite bivariate Bernstein operators and the cubature formula associated with them. The upper bounds for the remainder term of a cubature formula are described in terms of moduli of continuity of order two. Also, we include some results showing how nonmultiplicative the integration functional is.
\end{abstract}

\section{INTRODUCTION}

We reconsider (composite) bivariate Bernstein approximation and the corresponding cubature formulas. This is motivated by a recent series of articles by Bărbosu et al. (see [3], [4]). However, some of these papers contain rather misleading statements and claims which can hardly be verified. The present article is written with the intention to clean up some of the bugs, to optimize and generalize certain estimates, and thus to further describe the situation at hand.

Our present contribution is a continuation of [9]. Historically, the origin of the method discussed seems to be in the article [13] by D. D. Stancu and A. Vernescu.

\section{A GeNERAL RESULT}

We first introduce some notation that will be needed to formulate the general result.

Copyright 2016 by the Tusi Mathematical Research Group.

Received Mar. 8, 2015; Accepted May 28, 2015.

${ }^{*}$ Corresponding author.

2010 Mathematics Subject Classification. Primary 41A36; Secondary 41A15, 65D30.

Keywords. composite Bernstein operators, composite quadrature formulas, modulus of continuity. 


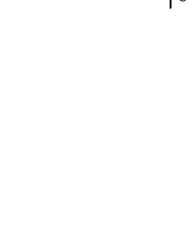

ANALYSIS
Banach J. Math. Anal. 10 (2016), no. 2, 235-250

http://dx.doi.org/10.1215/17358787-3492611

ISSN: $1735-8787$ (electronic)

http://projecteuclid.org/bjma

\title{
COMPOSITE BERNSTEIN CUBATURE
}

\author{
ANA-MARIA ACU ${ }^{*}$ and HEINER GONSKA ${ }^{2}$ \\ Communicated by R. E. Curto
}

\begin{abstract}
We consider a sequence of composite bivariate Bernstein operators and the cubature formula associated with them. The upper bounds for the remainder term of a cubature formula are described in terms of moduli of continuity of order two. Also, we include some results showing how nonmultiplicative the integration functional is.
\end{abstract}

\section{INTRODUCTION}

We reconsider (composite) bivariate Bernstein approximation and the corresponding cubature formulas. This is motivated by a recent series of articles by Bărbosu et al. (see [3], [4]). However, some of these papers contain rather misleading statements and claims which can hardly be verified. The present article is written with the intention to clean up some of the bugs, to optimize and generalize certain estimates, and thus to further describe the situation at hand.

Our present contribution is a continuation of [9]. Historically, the origin of the method discussed seems to be in the article [13] by D. D. Stancu and A. Vernescu.

\section{A GeNERAL RESULT}

We first introduce some notation that will be needed to formulate the general result.

Copyright 2016 by the Tusi Mathematical Research Group.

Received Mar. 8, 2015; Accepted May 28, 2015.

${ }^{*}$ Corresponding author.

2010 Mathematics Subject Classification. Primary 41A36; Secondary 41A15, 65D30.

Keywords. composite Bernstein operators, composite quadrature formulas, modulus of continuity. 


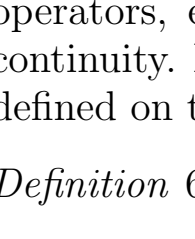

ANALYSIS
Banach J. Math. Anal. 10 (2016), no. 2, 235-250

http://dx.doi.org/10.1215/17358787-3492611

ISSN: $1735-8787$ (electronic)

http://projecteuclid.org/bjma

\title{
COMPOSITE BERNSTEIN CUBATURE
}

\author{
ANA-MARIA ACU ${ }^{*}$ and HEINER GONSKA ${ }^{2}$ \\ Communicated by R. E. Curto
}

\begin{abstract}
We consider a sequence of composite bivariate Bernstein operators and the cubature formula associated with them. The upper bounds for the remainder term of a cubature formula are described in terms of moduli of continuity of order two. Also, we include some results showing how nonmultiplicative the integration functional is.
\end{abstract}

\section{INTRODUCTION}

We reconsider (composite) bivariate Bernstein approximation and the corresponding cubature formulas. This is motivated by a recent series of articles by Bărbosu et al. (see [3], [4]). However, some of these papers contain rather misleading statements and claims which can hardly be verified. The present article is written with the intention to clean up some of the bugs, to optimize and generalize certain estimates, and thus to further describe the situation at hand.

Our present contribution is a continuation of [9]. Historically, the origin of the method discussed seems to be in the article [13] by D. D. Stancu and A. Vernescu.

\section{A GeNERAL RESULT}

We first introduce some notation that will be needed to formulate the general result.

Copyright 2016 by the Tusi Mathematical Research Group.

Received Mar. 8, 2015; Accepted May 28, 2015.

${ }^{*}$ Corresponding author.

2010 Mathematics Subject Classification. Primary 41A36; Secondary 41A15, 65D30.

Keywords. composite Bernstein operators, composite quadrature formulas, modulus of continuity. 


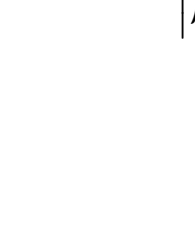

ANALYSIS
Banach J. Math. Anal. 10 (2016), no. 2, 235-250

http://dx.doi.org/10.1215/17358787-3492611

ISSN: $1735-8787$ (electronic)

http://projecteuclid.org/bjma

\title{
COMPOSITE BERNSTEIN CUBATURE
}

\author{
ANA-MARIA ACU ${ }^{*}$ and HEINER GONSKA ${ }^{2}$ \\ Communicated by R. E. Curto
}

\begin{abstract}
We consider a sequence of composite bivariate Bernstein operators and the cubature formula associated with them. The upper bounds for the remainder term of a cubature formula are described in terms of moduli of continuity of order two. Also, we include some results showing how nonmultiplicative the integration functional is.
\end{abstract}

\section{INTRODUCTION}

We reconsider (composite) bivariate Bernstein approximation and the corresponding cubature formulas. This is motivated by a recent series of articles by Bărbosu et al. (see [3], [4]). However, some of these papers contain rather misleading statements and claims which can hardly be verified. The present article is written with the intention to clean up some of the bugs, to optimize and generalize certain estimates, and thus to further describe the situation at hand.

Our present contribution is a continuation of [9]. Historically, the origin of the method discussed seems to be in the article [13] by D. D. Stancu and A. Vernescu.

\section{A GeNERAL RESULT}

We first introduce some notation that will be needed to formulate the general result.

Copyright 2016 by the Tusi Mathematical Research Group.

Received Mar. 8, 2015; Accepted May 28, 2015.

${ }^{*}$ Corresponding author.

2010 Mathematics Subject Classification. Primary 41A36; Secondary 41A15, 65D30.

Keywords. composite Bernstein operators, composite quadrature formulas, modulus of continuity. 


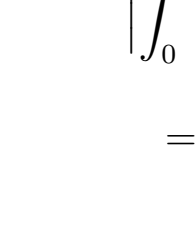

ANALYSIS
Banach J. Math. Anal. 10 (2016), no. 2, 235-250

http://dx.doi.org/10.1215/17358787-3492611

ISSN: $1735-8787$ (electronic)

http://projecteuclid.org/bjma

\title{
COMPOSITE BERNSTEIN CUBATURE
}

\author{
ANA-MARIA ACU ${ }^{*}$ and HEINER GONSKA ${ }^{2}$ \\ Communicated by R. E. Curto
}

\begin{abstract}
We consider a sequence of composite bivariate Bernstein operators and the cubature formula associated with them. The upper bounds for the remainder term of a cubature formula are described in terms of moduli of continuity of order two. Also, we include some results showing how nonmultiplicative the integration functional is.
\end{abstract}

\section{INTRODUCTION}

We reconsider (composite) bivariate Bernstein approximation and the corresponding cubature formulas. This is motivated by a recent series of articles by Bărbosu et al. (see [3], [4]). However, some of these papers contain rather misleading statements and claims which can hardly be verified. The present article is written with the intention to clean up some of the bugs, to optimize and generalize certain estimates, and thus to further describe the situation at hand.

Our present contribution is a continuation of [9]. Historically, the origin of the method discussed seems to be in the article [13] by D. D. Stancu and A. Vernescu.

\section{A GeNERAL RESULT}

We first introduce some notation that will be needed to formulate the general result.

Copyright 2016 by the Tusi Mathematical Research Group.

Received Mar. 8, 2015; Accepted May 28, 2015.

${ }^{*}$ Corresponding author.

2010 Mathematics Subject Classification. Primary 41A36; Secondary 41A15, 65D30.

Keywords. composite Bernstein operators, composite quadrature formulas, modulus of continuity. 


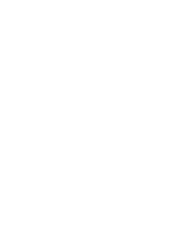

ANALYSIS
Banach J. Math. Anal. 10 (2016), no. 2, 235-250

http://dx.doi.org/10.1215/17358787-3492611

ISSN: $1735-8787$ (electronic)

http://projecteuclid.org/bjma

\title{
COMPOSITE BERNSTEIN CUBATURE
}

\author{
ANA-MARIA ACU ${ }^{*}$ and HEINER GONSKA ${ }^{2}$ \\ Communicated by R. E. Curto
}

\begin{abstract}
We consider a sequence of composite bivariate Bernstein operators and the cubature formula associated with them. The upper bounds for the remainder term of a cubature formula are described in terms of moduli of continuity of order two. Also, we include some results showing how nonmultiplicative the integration functional is.
\end{abstract}

\section{INTRODUCTION}

We reconsider (composite) bivariate Bernstein approximation and the corresponding cubature formulas. This is motivated by a recent series of articles by Bărbosu et al. (see [3], [4]). However, some of these papers contain rather misleading statements and claims which can hardly be verified. The present article is written with the intention to clean up some of the bugs, to optimize and generalize certain estimates, and thus to further describe the situation at hand.

Our present contribution is a continuation of [9]. Historically, the origin of the method discussed seems to be in the article [13] by D. D. Stancu and A. Vernescu.

\section{A GeNERAL RESULT}

We first introduce some notation that will be needed to formulate the general result.

Copyright 2016 by the Tusi Mathematical Research Group.

Received Mar. 8, 2015; Accepted May 28, 2015.

${ }^{*}$ Corresponding author.

2010 Mathematics Subject Classification. Primary 41A36; Secondary 41A15, 65D30.

Keywords. composite Bernstein operators, composite quadrature formulas, modulus of continuity. 


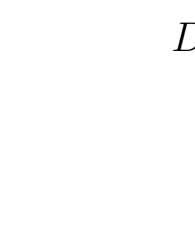

ANALYSIS
Banach J. Math. Anal. 10 (2016), no. 2, 235-250

http://dx.doi.org/10.1215/17358787-3492611

ISSN: $1735-8787$ (electronic)

http://projecteuclid.org/bjma

\title{
COMPOSITE BERNSTEIN CUBATURE
}

\author{
ANA-MARIA ACU ${ }^{*}$ and HEINER GONSKA ${ }^{2}$ \\ Communicated by R. E. Curto
}

\begin{abstract}
We consider a sequence of composite bivariate Bernstein operators and the cubature formula associated with them. The upper bounds for the remainder term of a cubature formula are described in terms of moduli of continuity of order two. Also, we include some results showing how nonmultiplicative the integration functional is.
\end{abstract}

\section{INTRODUCTION}

We reconsider (composite) bivariate Bernstein approximation and the corresponding cubature formulas. This is motivated by a recent series of articles by Bărbosu et al. (see [3], [4]). However, some of these papers contain rather misleading statements and claims which can hardly be verified. The present article is written with the intention to clean up some of the bugs, to optimize and generalize certain estimates, and thus to further describe the situation at hand.

Our present contribution is a continuation of [9]. Historically, the origin of the method discussed seems to be in the article [13] by D. D. Stancu and A. Vernescu.

\section{A GeNERAL RESULT}

We first introduce some notation that will be needed to formulate the general result.

Copyright 2016 by the Tusi Mathematical Research Group.

Received Mar. 8, 2015; Accepted May 28, 2015.

${ }^{*}$ Corresponding author.

2010 Mathematics Subject Classification. Primary 41A36; Secondary 41A15, 65D30.

Keywords. composite Bernstein operators, composite quadrature formulas, modulus of continuity. 


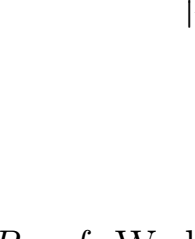

ANALYSIS
Banach J. Math. Anal. 10 (2016), no. 2, 235-250

http://dx.doi.org/10.1215/17358787-3492611

ISSN: $1735-8787$ (electronic)

http://projecteuclid.org/bjma

\title{
COMPOSITE BERNSTEIN CUBATURE
}

\author{
ANA-MARIA ACU ${ }^{*}$ and HEINER GONSKA ${ }^{2}$ \\ Communicated by R. E. Curto
}

\begin{abstract}
We consider a sequence of composite bivariate Bernstein operators and the cubature formula associated with them. The upper bounds for the remainder term of a cubature formula are described in terms of moduli of continuity of order two. Also, we include some results showing how nonmultiplicative the integration functional is.
\end{abstract}

\section{INTRODUCTION}

We reconsider (composite) bivariate Bernstein approximation and the corresponding cubature formulas. This is motivated by a recent series of articles by Bărbosu et al. (see [3], [4]). However, some of these papers contain rather misleading statements and claims which can hardly be verified. The present article is written with the intention to clean up some of the bugs, to optimize and generalize certain estimates, and thus to further describe the situation at hand.

Our present contribution is a continuation of [9]. Historically, the origin of the method discussed seems to be in the article [13] by D. D. Stancu and A. Vernescu.

\section{A GeNERAL RESULT}

We first introduce some notation that will be needed to formulate the general result.

Copyright 2016 by the Tusi Mathematical Research Group.

Received Mar. 8, 2015; Accepted May 28, 2015.

${ }^{*}$ Corresponding author.

2010 Mathematics Subject Classification. Primary 41A36; Secondary 41A15, 65D30.

Keywords. composite Bernstein operators, composite quadrature formulas, modulus of continuity. 


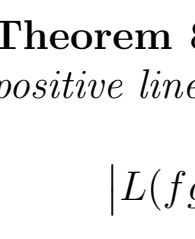

ANALYSIS
Banach J. Math. Anal. 10 (2016), no. 2, 235-250

http://dx.doi.org/10.1215/17358787-3492611

ISSN: $1735-8787$ (electronic)

http://projecteuclid.org/bjma

\title{
COMPOSITE BERNSTEIN CUBATURE
}

\author{
ANA-MARIA ACU ${ }^{*}$ and HEINER GONSKA ${ }^{2}$ \\ Communicated by R. E. Curto
}

\begin{abstract}
We consider a sequence of composite bivariate Bernstein operators and the cubature formula associated with them. The upper bounds for the remainder term of a cubature formula are described in terms of moduli of continuity of order two. Also, we include some results showing how nonmultiplicative the integration functional is.
\end{abstract}

\section{INTRODUCTION}

We reconsider (composite) bivariate Bernstein approximation and the corresponding cubature formulas. This is motivated by a recent series of articles by Bărbosu et al. (see [3], [4]). However, some of these papers contain rather misleading statements and claims which can hardly be verified. The present article is written with the intention to clean up some of the bugs, to optimize and generalize certain estimates, and thus to further describe the situation at hand.

Our present contribution is a continuation of [9]. Historically, the origin of the method discussed seems to be in the article [13] by D. D. Stancu and A. Vernescu.

\section{A GeNERAL RESULT}

We first introduce some notation that will be needed to formulate the general result.

Copyright 2016 by the Tusi Mathematical Research Group.

Received Mar. 8, 2015; Accepted May 28, 2015.

${ }^{*}$ Corresponding author.

2010 Mathematics Subject Classification. Primary 41A36; Secondary 41A15, 65D30.

Keywords. composite Bernstein operators, composite quadrature formulas, modulus of continuity. 


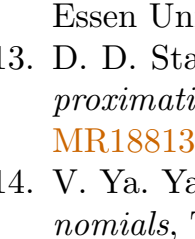

ANALYSIS
Banach J. Math. Anal. 10 (2016), no. 2, 235-250

http://dx.doi.org/10.1215/17358787-3492611

ISSN: $1735-8787$ (electronic)

http://projecteuclid.org/bjma

\title{
COMPOSITE BERNSTEIN CUBATURE
}

\author{
ANA-MARIA ACU ${ }^{*}$ and HEINER GONSKA ${ }^{2}$ \\ Communicated by R. E. Curto
}

\begin{abstract}
We consider a sequence of composite bivariate Bernstein operators and the cubature formula associated with them. The upper bounds for the remainder term of a cubature formula are described in terms of moduli of continuity of order two. Also, we include some results showing how nonmultiplicative the integration functional is.
\end{abstract}

\section{INTRODUCTION}

We reconsider (composite) bivariate Bernstein approximation and the corresponding cubature formulas. This is motivated by a recent series of articles by Bărbosu et al. (see [3], [4]). However, some of these papers contain rather misleading statements and claims which can hardly be verified. The present article is written with the intention to clean up some of the bugs, to optimize and generalize certain estimates, and thus to further describe the situation at hand.

Our present contribution is a continuation of [9]. Historically, the origin of the method discussed seems to be in the article [13] by D. D. Stancu and A. Vernescu.

\section{A GeNERAL RESULT}

We first introduce some notation that will be needed to formulate the general result.

Copyright 2016 by the Tusi Mathematical Research Group.

Received Mar. 8, 2015; Accepted May 28, 2015.

${ }^{*}$ Corresponding author.

2010 Mathematics Subject Classification. Primary 41A36; Secondary 41A15, 65D30.

Keywords. composite Bernstein operators, composite quadrature formulas, modulus of continuity. 